\title{
Assessment of Performance Obstacles as Perceived by Nurses in Intensive Care Units.
}

\author{
Sabah Anwar Ragab, Mohamed Ali Mohamed Al Torky \& Soad Ahmed Ghallab.
}

General Manger of Nursing at Assuit University Hospitals, Egypt.

Professor of Community Medicine, Faculty of Medicine, Sohag University, Egypt.

Assist. Prof of Nursing Administration, Faculty of Nursing, Assuit University, Egypt.

\begin{abstract}
Background: Several factors were detected in ICU nurses' work system that can hinder their activity. Aim: The aim of the study was to investigate performance obstacles in ICUs nurses at Assuit University Hospitals. Setting The present study was carried out in the intensive care units at seven specialties at Assiut University Hospitals. Subjects: The study sample was 194 staff nurses who were working as bedside nurses in seven ICUs and who were willing to participate in the study. Tools: Data of the present collected through utilizing the following two tools personal characteristic: performance obstacles ICUs questionnaire Results: influential performance obstacles items were that the nursing staff was not enough to handle the number of patient, had difficulty finding a space to sit down and do any paperwork in their unit nurses, complain of the equipment in bad condition and there was a delay in getting medicines for patients. Recommendations: It is recommended that: When planning for a new or renovated critical care units, the health care facility should consults an expert in the field of hospital design as well as taking consideration about nurses and patients needs related to infrastructure of the unit.
\end{abstract}

\section{Keywords: Performance, Obstacles \& Intensive Care.}

\section{Introduction}

Many studies had been carried out on working conditions and psychosocial work factors in the work environment of intensive care units' nurses. Nevertheless, these studies did not have much influence on the improvement of intensive care unit nurses' work, most likely, It's because of the lack of the detailed examining of the intensive care units' work system which is necessary in order to identify where to focus improvements and align efforts in intensive care units (Institute of Medicine, 2004).

Intensive care unit is dynamic environments in decisions about patients' status are changed fast and decisions are often made under high stress and time pressure. The ICU work system is believed to be Clinical Microsystems that need to be studied thoroughly in order to identify reasons contributing to patients' poor safety and productivity of nursing (Carayon, et al., 2006).

Ulrich, et al., (2008), reported that five work processes affect performance, quality, and safety of care. These are (1) documentation, (2) medication administration, (3) communication, (4) care coordination, and (5) supplies and equipment management. Moreover Carayon, \& Gurses (2009), who added that performance obstacles are related to work environment, family relation, information transfer \& communication, and getting help from other.

Performance obstacles can be used to study work system design. Performance obstacles are "the work system characteristics that inhibit performance and are closely associated with the immediate work setting" of ICU nurses that increase their workload (Tucker,\& Edmondson, 2003 \& Carayon, et al., 2005).

Managers who are committed to managing for maximum performance recognize that one of their major responsibilities is to eliminate roadblocks to successful performance. Another is to provide adequate resources, to pay careful attention to selecting employees, all of which are part of performance facilitation (Grensing, \& Pophal, 2001). When organizational structure factors support the care processes and enable teamwork, nurses are more satisfied with their jobs, (Schmalenbberg, \& Kramer, 2007), and patients receive higher-quality care. Leaders, who engage in transactional, establish trust in relationships with staff, provide structure and expectations (Murphy, 2005), and transformational leadership, develops a stronger collective identity and commitment to change.

\section{Significance of the study}

During the investigator's work as a General Manager of Nursing at Assiut University Hospital, it was observed that intensive care units practice was filled with high nursing workload situations and there were several performance obstacles in the work' system that could hinder nurses' performance. Some nurses wanted to leave ICUs and this, in turn, led to the shortage in the number of ICUs nursing staff which affected the quality and safety of care and led to a low degree of nurses' satisfaction. Therefore, I 
decided to investigate performance obstacles, at Assuit University Hospitals, to help in removing performance obstacles, reducing nurses' workload and improving nurses' satisfaction.

Study methods:-

\section{The Aim of this study}

was to investigate performance obstacles experienced by intensive care nurses in their work environment.

\section{Design}

The present study was a descriptive and analytical study, follows a cross-sectional study design content, (1) performance obstacles in seven ICU at Assiut University Hospitals

Research questions: What are the performance obstacles that face nurses in ICU?

\section{Setting}

The study was conducted in seven intensive care units (ICUs) at Assiut University Hospitals bed capacity 100 beds in the units (Trauma, general, pediatric, obstetric, chest, Neuromedical and tropical).

\section{Sample}

A convenience sample of 194 staff nurses who were working in the aforementioned intensive care units at Assiut University Hospitals. Distributed in the units as follows:

\begin{tabular}{|l|l|l|}
\hline Name of ICUs & $\begin{array}{l}\text { Number of staff } \\
\text { nurses No=(194) }\end{array}$ & \% \\
\hline Trauma & 59 & 30.4 \\
\hline General & 41 & 21.1 \\
\hline Chest & 39 & 20.1 \\
\hline tropical & 15 & 7.7 \\
\hline pediatric & 15 & 7.7 \\
\hline obstetric, & 15 & 7.7 \\
\hline Neuromedical & 10 & 5.2 \\
\hline
\end{tabular}

\section{Tools}

A structured interview questionnaire developed by Gurses, (2005) and modified by the researcher in order to become suitable to carry out the study. It consists of two parts:

\section{Part one}

Unit name

- Personal characteristic of study subjects: It is designed to gather data about the respondents' gender, age, marital status, nurse qualification, current job title, years of experience, and shift hours of work, and five questions about information of units, No of assistant in shift

- No of patients for which the nurse takes care of during the shift.

- No of patients admitted during the shift.

- No of patients transfer to other units.

- No of patients isolated.

\section{Part two}

Performance obstacles questionnaire: It is consists of six dimensions contains 40 items. the subitems divided as the following:-

- Physical work environment (10 items).

- Family relations (4 items).

- Supplies and Equipments (8 items).

- Information transfer and communication (7 items).

- Cooperation and helping others and getting help from others ( 7 items).

- Records and reports (4 items).

- Answer of questions will be by (Yes =1) or (No =2) (Sometimes = 3).

In addition to one, open question for any special event or circumstance that affected (increased or decreased) nurse workload during shift.

- Pilot study: was fulfilled on 20 nurses by using the structured interview for testing its feasibility, understandability, reliability, and validity. The first time, Cronbach alpha coefficient was $\mathbf{0 . 6 0}$, modification of study tools was done and the pilot study was repeated again, Cronbach alpha coefficient was 0.91 .

\section{- Ethical considerations}

- An official approval to carry out the study was obtained from responsible persons in the selected hospitals to be able to collect the necessary data. For the pilot study and then to collect the necessary data for the present study. Ethical consideration was taken through oral agreement from all nurses who were participated in the study at the intensive care units.

\section{Procedure}

The data phase of the present study was carried out within four months period started from June to October, (2016). The researcher selected seven head nurses to help her to collection data from nurses. The researcher trained them, the training included; explaining each item included in the study tools the training took 30 minutes. After ensuring the clarity of the tools, the actual data collection started. The questionnaire was collected from three shifts (morning, evening, and night), it was filled out in the last 30 minutes of the shift.

Statistical analysis: The collected data will be analyzed, using the appropriate statistical tests utilizing the SPSS statistical package for personal computers. Data entry and data analysis were done using SPSS version 19 (Statistical Package for Social Science). Data were presented as number, percentage, mean, standard deviation. P-value considered statistically significant when $\mathrm{P}<0.05$. 


\section{Results}

Table (1): Description and characteristics of the studied nurses.

\begin{tabular}{|c|c|c|}
\hline Items & No. $(n=194)$ & $\%$ \\
\hline \multicolumn{3}{|l|}{ Age } \\
\hline$<25$ years & 110 & 56.7 \\
\hline $25-<35$ years & 78 & 40.2 \\
\hline $35-<45$ years & 5 & 2.6 \\
\hline$\geq 45$ years & 1 & 0.5 \\
\hline \multicolumn{3}{|l|}{ Marital status } \\
\hline Single & 95 & 49.0 \\
\hline Married & 97 & 50.0 \\
\hline Widow & 1 & 0.5 \\
\hline Divorced & 1 & 0.5 \\
\hline \multicolumn{3}{|l|}{ Education } \\
\hline Secondary Nursing School & 96 & 49.5 \\
\hline Technical Health Institute & 67 & 34.5 \\
\hline Nursing Bachelor & 31 & 16.0 \\
\hline \multicolumn{3}{|l|}{ Job } \\
\hline \multicolumn{3}{|l|}{ Years of experience } \\
\hline$<1$ year & 65 & 33.5 \\
\hline $1-<5$ years & 61 & 31.4 \\
\hline $5-<10$ years & 29 & 14.9 \\
\hline $10-<15$ years & 32 & 16.5 \\
\hline $15-<20$ years & 4 & 2.1 \\
\hline$\geq 20$ years & 3 & 1.5 \\
\hline \multicolumn{3}{|c|}{ Shift type when questionnaire was filled out } \\
\hline Morning & 73 & 37.6 \\
\hline Evening & 55 & 28.4 \\
\hline Night & 66 & 34.0 \\
\hline \multicolumn{3}{|l|}{ Working hours per shift: } \\
\hline 7 hours & 73 & 37.6 \\
\hline 6 hours & 55 & 28.4 \\
\hline 12 hours & 66 & 34.0 \\
\hline
\end{tabular}

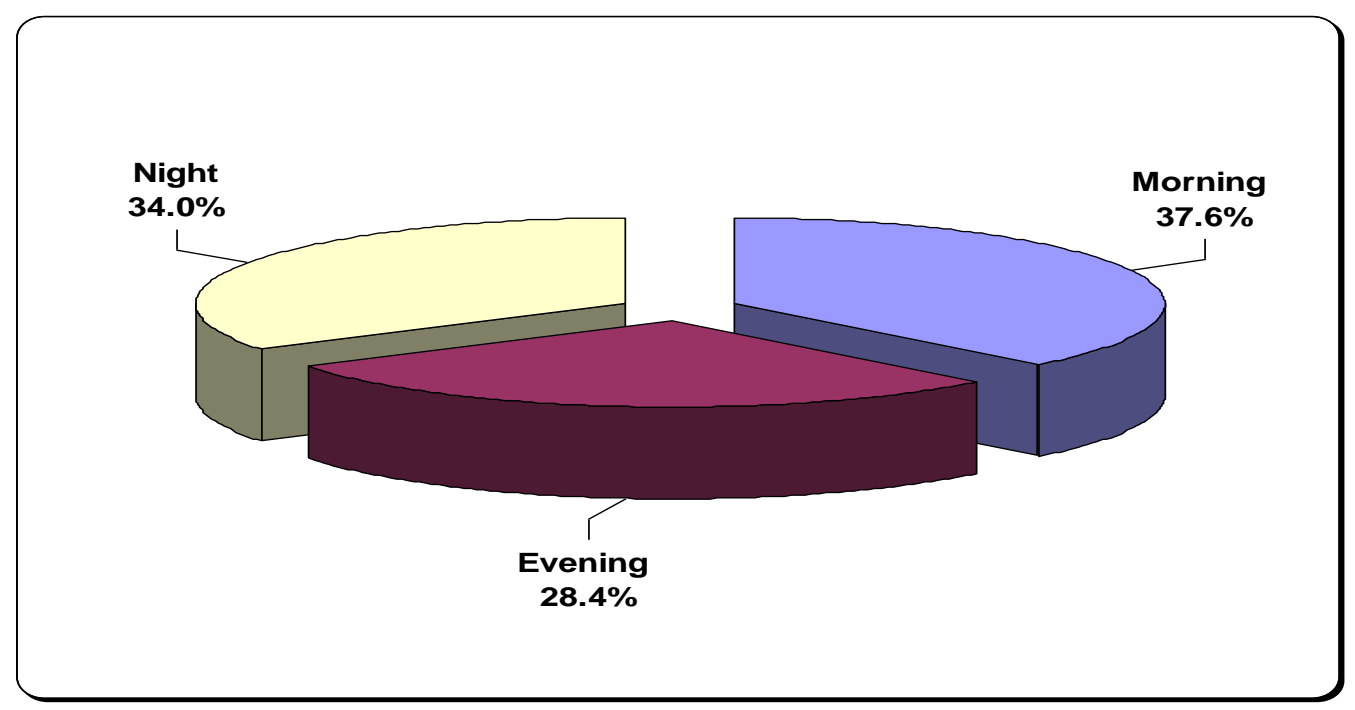

Figure (1):- percentage distribution of nurses regarding work time as perceived by the studied nurses. 


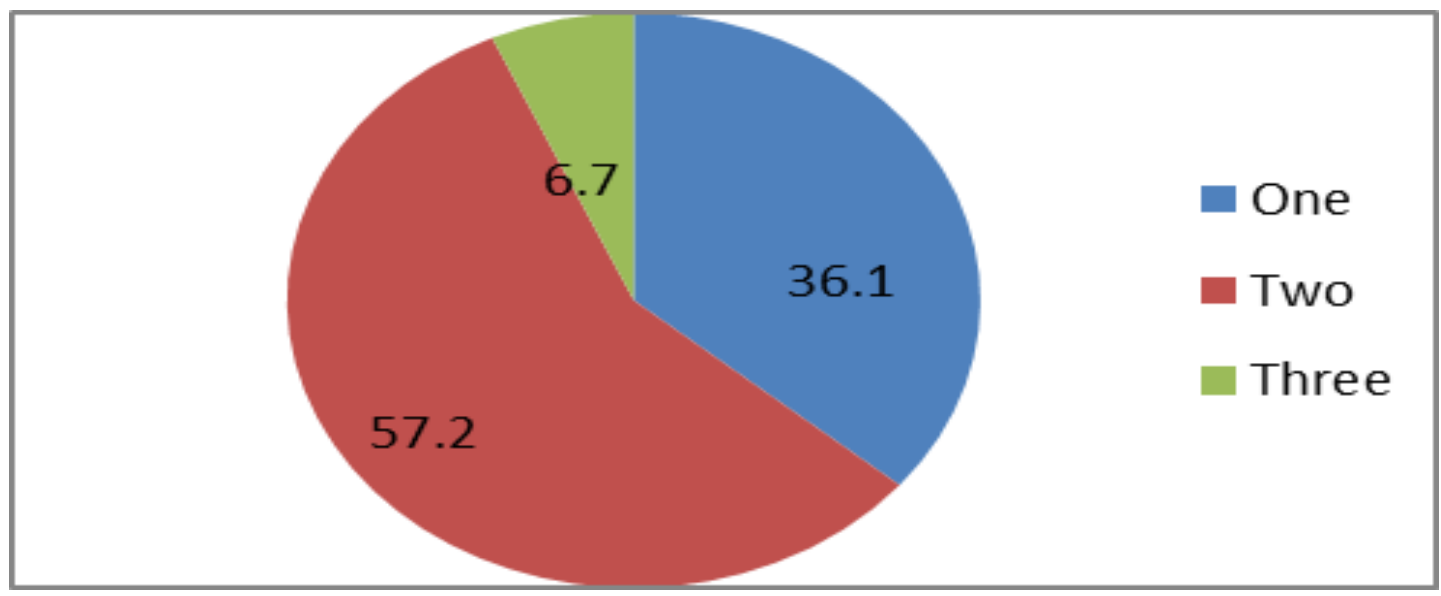

Figure (2) number of patients assigned to nurse during shift as perceived by the studied nurses

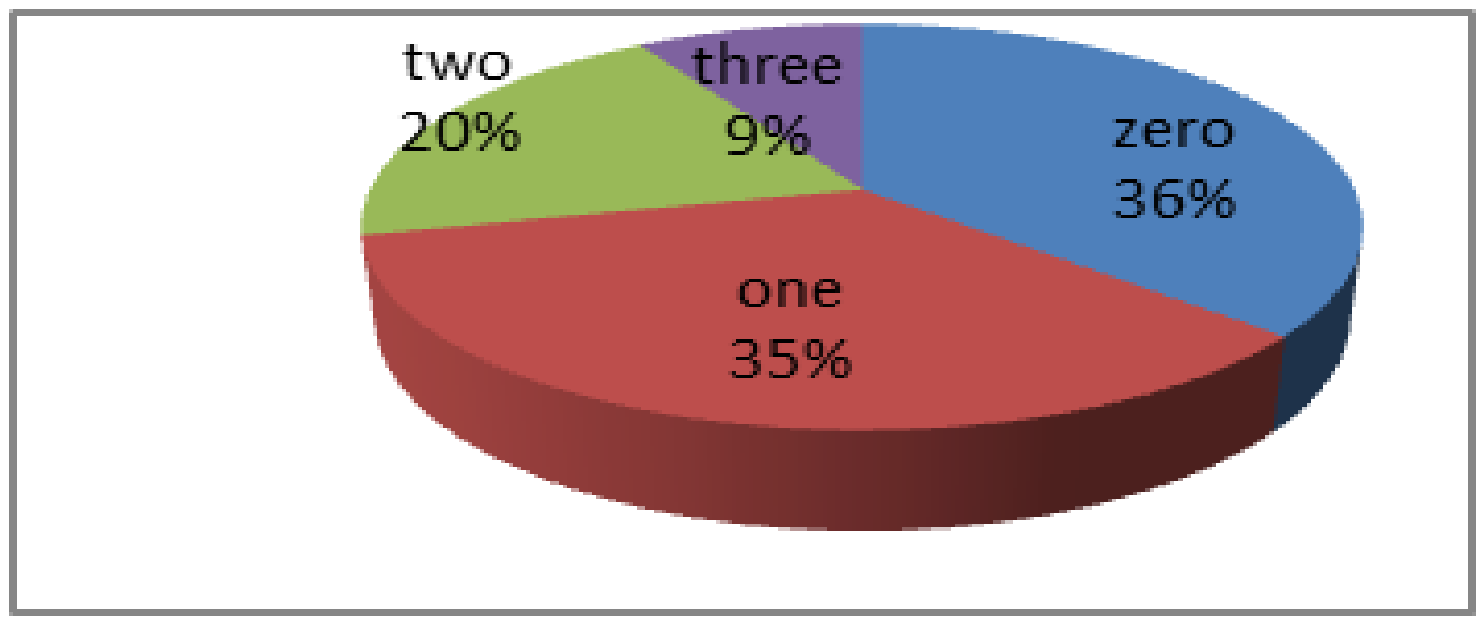

Figure (3) number of assistant nurse in the unit as perceived by the studied nurses

Table (2): frequency of performance obstacles related to Physical work environment as perceived by the studied nurses $(n=194)$.

\begin{tabular}{|l|c|c|c|c|c|c|}
\hline \multirow{2}{*}{\multicolumn{1}{|c|}{ Items }} & \multicolumn{2}{c|}{ Yes } & \multicolumn{2}{c|}{ Sometimes } & \multicolumn{2}{c|}{ No } \\
\cline { 2 - 7 } & No. & \% & No & \% & No. & \% \\
\hline Physical work environment & & & & & & \\
\hline $\begin{array}{l}\text { I had difficulty finding a space to sit down and } \\
\text { do any paperwork in this unit }\end{array}$ & 91 & 46.9 & 4 & 2.1 & 99 & 51.0 \\
\hline No enough space between beds & 78 & 40.2 & 4 & 2.1 & 112 & 57.7 \\
\hline My workplace was crowded & 78 & 40.2 & 3 & 1.5 & 113 & 58.2 \\
\hline The visit had no fixed time & 52 & 26.8 & 1 & 0.5 & 141 & 72.7 \\
\hline $\begin{array}{l}\text { The amount of space is not commensurate with } \\
\text { the number }\end{array}$ & 69 & 35.6 & 1 & 0.5 & 124 & 63.9 \\
\hline Hand washing basins close to nursing station. & 109 & 56.2 & 0 & 0.0 & 85 & 43.8 \\
\hline There is no proper ventilation in place & 78 & 40.2 & 1 & 0.5 & 115 & 59.3 \\
\hline storage place not far from the unit & 122 & 62.9 & 2 & 1.0 & 70 & 36.1 \\
\hline $\begin{array}{l}\text { Have not enough staff to handle the number of } \\
\text { patients }\end{array}$ & 160 & 82.5 & 4 & 2.1 & 30 & 15.5 \\
\hline $\begin{array}{l}\text { No isolation rooms for patients who need } \\
\text { isolation }\end{array}$ & 101 & 52.1 & 1 & 0.5 & 92 & 47.4 \\
\hline
\end{tabular}


Table (3): frequency of performance obstacles related to patient families relation as perceived by the studied nurses $(\mathbf{n}=194)$.

\begin{tabular}{|l|c|c|c|c|c|c|}
\hline \multicolumn{1}{|c|}{ Items } & \multicolumn{2}{c|}{ Yes } & \multicolumn{2}{c|}{ Sometimes } & \multicolumn{2}{c|}{ No } \\
\hline \multicolumn{1}{|c|}{ Family relations } & No. & $\%$ & No. & $\%$ & No. & $\%$ \\
\hline $\begin{array}{l}\text { Are there distractions from family } \\
\text { members? }\end{array}$ & 127 & 65.5 & 3 & 1.5 & 64 & 33.0 \\
\hline $\begin{array}{l}\text { Are you spending too much time to meet } \\
\text { patient's family needs? }\end{array}$ & 53 & 27.3 & 1 & 0.5 & 140 & 72.2 \\
\hline $\begin{array}{l}\text { Is there loss of a time in interviewing } \\
\text { family's patients? }\end{array}$ & 70 & 36.1 & 4 & 2.1 & 120 & 61.9 \\
\hline $\begin{array}{l}\text { Having to spend too much time teaching } \\
\text { and supported patient's families? }\end{array}$ & 71 & 36.6 & 4 & 2.1 & 119 & 61.3 \\
\hline
\end{tabular}

Table (4): frequency of performance obstacles related to supplies and equipment as perceived by the studied nurses $(n=194)$.

\begin{tabular}{|l|c|c|c|c|c|c|c|}
\hline \multirow{2}{*}{ Items } & \multicolumn{2}{c|}{ Yes } & \multicolumn{2}{c|}{ Sometimes } & \multicolumn{2}{c|}{ No } \\
\cline { 2 - 8 } Supplies and equipment & No. & \% & No & \% & No. & \% \\
\hline \multicolumn{1}{|c|}{} & \multicolumn{2}{|c|}{} & \multicolumn{1}{|c|}{} & & \\
\hline $\begin{array}{l}\text { Spending time seeking for supplies in the supply } \\
\text { area because supplies not organized (supplies } \\
\text { misplaced) }\end{array}$ & 91 & 46.9 & 2 & 1.0 & 101 & 52.1 \\
\hline Delays in getting medications from pharmacy & 109 & 56.2 & 2 & 1.0 & 83 & 42.8 \\
\hline $\begin{array}{l}\text { There was a delay in administering medications } \\
\text { for my patients due to a problem with the } \\
\text { medication receiving system }\end{array}$ & 85 & 43.8 & 10 & 5.2 & 99 & 51.0 \\
\hline $\begin{array}{l}\text { Have no enough supplies for the patients that } \\
\text { affect performance quality. }\end{array}$ & 114 & 58.8 & 8 & 4.1 & 72 & 37.1 \\
\hline equipment are not located in the right place & 95 & 49.0 & 2 & 1.0 & 97 & 50.0 \\
\hline equipment are not adequate & 123 & 63.4 & 6 & 3.1 & 65 & 33.5 \\
\hline equipment was in poor condition & 118 & 60.8 & 8 & 4.1 & 68 & 35.1 \\
\hline $\begin{array}{l}\text { Spent much time searching for equipment and } \\
\text { supplies in my unit. }\end{array}$ & 104 & 53.6 & 4 & 2.1 & 86 & 44.3 \\
\hline
\end{tabular}

Table (5): frequency of performance obstacles related to Information transfer \& communication as perceived by the studied nurses $(n=194)$.

\begin{tabular}{|l|c|c|c|c|c|c|}
\hline \multicolumn{1}{|c|}{ Items } & \multicolumn{2}{c|}{ yes } & \multicolumn{2}{c|}{ Sometimes } & \multicolumn{2}{c|}{ No } \\
\hline Information transfer and communication & No. & $\mathbf{\%}$ & No. & \% & No. & \% \\
\hline I spent much time searching for my patients' charts & 53 & 27.3 & 2 & 1.0 & 139 & 71.6 \\
\hline $\begin{array}{l}\text { There was a delay before I saw the new medical } \\
\text { orders for my patient(s) }\end{array}$ & 44 & 22.7 & 0 & 0.0 & 150 & 77.3 \\
\hline Report taking too long time. & 81 & 41.8 & 4 & 2.1 & 109 & 56.2 \\
\hline $\begin{array}{l}\text { Unnecessarily detailed information given by previous } \\
\text { shift's nurse during handoff report }\end{array}$ & 65 & 33.5 & 3 & 1.5 & 126 & 64.9 \\
\hline $\begin{array}{l}\text { Inadequate information given by previous shift's } \\
\text { nurse during handoff report }\end{array}$ & 61 & 31.4 & 2 & 1.0 & 131 & 67.5 \\
\hline $\begin{array}{l}\text { Inadequate information from physicians in the } \\
\text { patient's charts }\end{array}$ & 74 & 38.1 & 3 & 1.5 & 117 & 60.3 \\
\hline The doctor in charge is not easily accessible & 111 & 57.2 & 5 & 2.6 & 78 & 40.2 \\
\hline
\end{tabular}


Table (6): frequency of performance obstacles related to cooperation as perceived by the studied nurses $(\mathbf{n}=194)$.

\begin{tabular}{|l|c|c|c|c|c|c|c|}
\hline \multicolumn{1}{|c|}{ Items } & \multicolumn{2}{c|}{ Yes } & \multicolumn{2}{c|}{ Sometimes } & \multicolumn{2}{c|}{ No } \\
\cline { 2 - 7 } & No. & \% & No & \% & No & \% \\
\hline Cooperation & \multicolumn{7}{|c|}{} \\
\hline I have a reasonable patient workload. & 71 & 36.6 & 4 & 2.1 & 119 & 61.3 \\
\hline I have the chance to help other nurses with their Patients' needs. & 127 & 65.5 & 2 & 1.0 & 65 & 33.5 \\
\hline I have responsibility in new nurses'orientation. & 146 & 75.3 & 5 & 2.6 & 43 & 22.2 \\
\hline I have help from nursing assistants & 143 & 73.7 & 3 & 1.5 & 48 & 24.7 \\
\hline I have help from other nurses. & 157 & 80.9 & 2 & 1.0 & 35 & 18.0 \\
\hline I have help from unit clerks & 157 & 80.9 & 1 & .5 & 36 & 18.6 \\
\hline $\begin{array}{l}\text { All staff in the unit work well together to provide the best } \\
\text { care for patients }\end{array}$ & 124 & 63.9 & 6 & 3.1 & 64 & 33.0 \\
\hline
\end{tabular}

Table (7): frequency of performance obstacles related to records \& reports as perceived by the studied nurses $(\mathbf{n = 1 9 4 )}$.

\begin{tabular}{|l|c|c|c|c|c|c|}
\hline \multicolumn{1}{|c|}{ Items } & \multicolumn{2}{c|}{ Yes } & \multicolumn{3}{c|}{ Sometimes } & \multicolumn{2}{c|}{ No } \\
\hline \multicolumn{1}{|c|}{ Records and reports } & No. & \% & No. & \% & No. & \% \\
\hline All the serious mistakes are reported at that moment. & 128 & 66.0 & 7 & 3.6 & 59 & 30.4 \\
\hline All patient problems are recorded? & 121 & 62.4 & 6 & 3.1 & 67 & 34.5 \\
\hline There are incident reports. & 80 & 41.2 & 0 & 0.0 & 114 & 58.8 \\
\hline Rate of nosocomial infections are recorded. & 70 & 36.1 & 4 & 2.1 & 120 & 61.9 \\
\hline
\end{tabular}

Table (8): Distribution of performance obstacles from the studied nurses point of view $\quad(n=194)$.

\begin{tabular}{|l|c|c|c|}
\hline \multicolumn{1}{|c|}{ Variables } & No. $(\mathbf{n = 9 0 )}$ & Rank & \% \\
\hline Ineffective interpersonal relationships & 27 & 1 & 30 \\
\hline Shortage of nurses(nurses not enough) & 16 & 2 & 17.77 \\
\hline sudden absence of nurses & 14 & 3 & 15.56 \\
\hline sudden absence of assistant nurse & 8 & 4 & 8.89 \\
\hline Shortage of assistants & 7 & 5 & 7.77 \\
\hline High admission rates during the shift & 6 & 6 & 6.66 \\
\hline Shortage of needed drugs in the shift. & 5 & 7 & 5.55 \\
\hline In availability maintenance personnel in the shift. & 3 & 8 & 3.33 \\
\hline Absence of housekeeping worker in the shift. & 2 & 9 & 2.22 \\
\hline Recording sometimes incomplete & 2 & 9 & 2.22 \\
\hline
\end{tabular}

Table (9): Relation between means of performance obstacles subitems and ICUs specialty as perceived by the studied nurses

\begin{tabular}{|l|c|c|c|c|c|c|c|c|}
\hline \multirow{2}{*}{$\begin{array}{c}\text { Items of Performance } \\
\text { obstacles }\end{array}$} & Neuro & Tropical & Obstetric & Chest & Trauma & General & Pediatrics & P-value \\
\cline { 2 - 9 } & Mean \pm SD & Mean \pm SD & $\begin{array}{c}\text { Mean } \pm \\
\text { SD }\end{array}$ & $\begin{array}{c}\text { Mean } \pm \\
\text { SD }\end{array}$ & $\begin{array}{c}\text { Mean } \pm \\
\text { SD }\end{array}$ & Mean \pm SD & Mean \pm SD & P-val \\
\hline $\begin{array}{l}\text { Physical work } \\
\text { environment }\end{array}$ & $7.50 \pm 3.10$ & $15.33 \pm 3.98$ & $9.07 \pm 5.50$ & $4.72 \pm 2.99$ & $9.31 \pm 3.65$ & $9.02 \pm 3.70$ & $13.40 \pm 2.59$ & $0.000^{* * *}$ \\
\hline Family relations & $4.60 \pm 3.13$ & $6.93 \pm 2.12$ & $3.33 \pm 2.47$ & $4.10 \pm 3.24$ & $2.41 \pm 2.07$ & $3.17 \pm 2.39$ & $1.47 \pm 1.60$ & $0.000^{* * * *}$ \\
\hline Supplies equipment & $6.20 \pm 3.58$ & $14.53 \pm 2.33$ & $9.33 \pm 4.19$ & $7.41 \pm 5.16$ & $8.12 \pm 4.94$ & $10.80 \pm 4.31$ & $5.93 \pm 3.88$ & $0.000^{* * * *}$ \\
\hline $\begin{array}{l}\text { Information transfer } \\
\text { and communication }\end{array}$ & $5.70 \pm 4.00$ & $11.60 \pm 3.72$ & $3.60 \pm 3.79$ & $5.38 \pm 4.13$ & $3.76 \pm 3.02$ & $6.10 \pm 3.29$ & $2.00 \pm 2.00$ & $0.000^{* * * *}$ \\
\hline Cooperation & $9.70 \pm 2.58$ & $9.20 \pm 5.44$ & $9.20 \pm 2.81$ & $9.15 \pm 3.04$ & $0.44 \pm 3.30$ & $9.15 \pm 3.50$ & $10.13 \pm 2.70$ & 0.481 \\
\hline Records and reports & $3.80 \pm 1.69$ & $6.00 \pm 2.27$ & $4.40 \pm 2.64$ & $4.21 \pm 2.74$ & $3.39 \pm$ & $4.71 \pm 2.40$ & $4.27 \pm 2.60$ & $0.025 * *$ \\
\hline
\end{tabular}




\begin{tabular}{|c|c|c|c|c|c|c|c|c|}
\hline $\begin{array}{c}\text { Items of Performance } \\
\text { obstacles }\end{array}$ & Neuro & Tropical & Obstetric & Chest & Trauma & General & Pediatrics & \\
\cline { 2 - 8 } & Mean \pm SD & Mean \pm SD & $\begin{array}{c}\text { Mean } \pm \\
\text { SD }\end{array}$ & $\begin{array}{c}\text { Mean } \pm \\
\text { SD }\end{array}$ & $\begin{array}{c}\text { Mean } \pm \\
\text { SD }\end{array}$ & Mean \pm SD & Mean \pm SD & P-value \\
\hline & & & & & 2.80 & & & \\
\hline Total obstacles & $37.50 \pm$ \\
& 10.92 & $\begin{array}{c}63.60 \pm \\
17.06\end{array}$ & $\begin{array}{c}38.93 \pm \\
15.91\end{array}$ & $\begin{array}{c}34.97 \pm \\
13.51\end{array}$ & $\begin{array}{c}37.42 \pm \\
10.48\end{array}$ & $\begin{array}{c}42.95 \pm \\
10.20\end{array}$ & $37.20 \pm 5.87$ & $0.000 * * *$ \\
\hline
\end{tabular}

The difference is very highly significant at, $p<0.0001 * * *)$

0 The difference is significant at, $p<0.05$

Table (1): Description and characteristics of the studied nurses. Shows that the vast majority (97\%) of studied nurses were in the age group ranged between $25<35$ years, half of them $(50 \%)$ were married. Also this table shows that nearly half of them $(49.5 \%)$ having diploma of secondary nursing School (five years), while (64.9\%) of them have less than 5 years of experience in nursing. Regarding, distribution of working hours $(37.6 \%)$ of them were working 7 hours morning shift, $(28.4 \%)$ of them were working 6 hours evening shift, and $(34.0 \%)$ of them were working 12 hours night shift, and all of them were working as bedside nurses giving direct care.

Figure (1): Displays that more than one third $(37.6 \%)$ of the studied nurses were working in the morning shift.

Figure (2): Displays that more than half $(57.2 \%)$ of the studied nurses reported that the patient numbers to whom they were responsible were two patients.

Figure (3): Shows that more than one third (36\%) of studied nurses reported that number of assistant nurse in their units was zero.

Table (2): Depicts that the performance obstacles related to physical work environment as perceived by the studied nurses. The majority $(82.5 \%)$ of them had no enough staff to handle the number of patients, and also $(62.9 \%)$ of them said that storage place was not far from unit, more than half $(52.1 \%)$ of studied nurses stated that they had no isolation rooms for patients who need isolation and hand washing basins close to nursing station. While nearly to half $(46.9 \%)$ of them had difficulty in finding a space to sit down and do any paperwork in their unit.

Table (3): Shows that about two thirds (65.5\%) of them were suffering from distractions from patients' family members, while more than a quarter $(27.3 \%)$ of them were spending too much time to meet patients' family needs.

Table (4): Shows that nearly two thirds, (63.4\%) of them had to wait to use a piece of equipment because someone else was using it, and more than half $(60.8 \%)$ of them said that they used equipment which was in poor condition. Also, this table shows that more than half $(58.8 \%)$ of the studied nurses had no enough supplies for the patients which affect performance quality, while nearly half $(43.8 \%)$ were suffering from delay in administering medications for their patients due to a problem with the medication receiving system.

Table (5): Displays that. more than half (57.2\%) of them said that The doctor in charge is not easily accessible to contact about one of the patients, while near a quarter $(22.7 \%)$ of them said that there was a delay before they saw the new medical orders for their patients.

Table (6): Shows that more than half $(61.3 \%)$ of them had no reasonable patient workload, about onethird $(33.5 \%)$ of the studied nurses had no chance to help other nurses with their patients' needs and they did not work well together to provide the best care for patients while only (18.0\%) of the studied nurses had not received help from other nurses and (18.6\%) of them were not helped by unit clerks.

Table (7): Reveals that two -thirds $(66.0 \%)$ of them said that all the serious mistakes are reported, about two-thirds (62.4\%) of them reported that All patient problems are recorded, while more than half (61.9\%) of them said that rate of nosocomial infections are recorded and $(58.8 \%)$ of them agreed that there was no incident report.

Table (8): Shows that there were (90) nurses from the total studied nurses who mentioned another performance obstacles that increase their workload during the shift $(30 \%)$ of them mentioned ineffective interpersonal relationships, $(17.77 \%)$ of them reported shortage of nurses during the shift, $(15.56 \%)$ of them agreed that sudden absence of nurses during shift. While only $(2.22 \%)$ of them said that recording sometimes was incomplete.

Table (9): Shows the relation between means \pm SD of items of performance obstacles and ICUs specialty. As presented in the table there was a clear difference between the mean of subitems of performance obstacle in ICUs specialty, except the mean and standard deviation of cooperation which differences were mild with the different specialty ICUs and these differences were not statistically significant. The mean and standard deviation, of physical work environment obstacles was $(15.33 \pm$ 3.98) for tropical ICU compared to $(4.72 \pm 2.99)$ for chest ICU. In addition, the mean and standard deviation of family relations obstacles was $(6.93 \pm$ $2.12)$, supplies \& equipment was $(14.53 \pm 2.33)$ and information transfer \& communication was (11.60 \pm 3.72) for tropical ICU compared to $(1.47 \pm 1.60)$, 
$(5.93 \pm 3.88)$ and $(2.00 \pm 2.00)$ for pediatrics. In addition, the mean and standard deviation of records $\&$ reports were $(6.00 \pm 2.27)$ for tropical ICU compared to $(3.39 \pm 2.80)$ for trauma ICU and the mean of total performance obstacles was (63.60 \pm 17.06) for tropical ICU compared to $(34.97 \pm 13.51)$ for chest ICU. There was statistically highly significant difference between performance obstacles related to; physical work environment, family relations, supplies \& equipment, Information transfer \& communication, records and reports and total performance obstacles with ICUs specialty $(\mathrm{p}<0.000 * * *)$.

\section{Discussion}

Performance obstacles can be used to study work system design. Performance obstacles are "the work system characteristics that inhibit performance and are closely associated with the immediate work setting' of ICU nurses that increase their workload beyond what is expected (Tucker,\& Edmondson, 2003) High workload has been identified as a major concern in health care, particularly in intensive care units (ICUs). Patient care in the ICU is characterized by highly demanding tasks that need to support urgent therapeutic intervention. The aim of the present study was to assess performance obstacles in ICUs. Performance obstacles are factors that hinder nurses 'capacity to perform their job and that was closely associated with their immediate work system at Assiut university hospitals in 7 ICUs. The study included all staff nurses who worked as bedside nurses (194) that were distributed as follows: neuromedical 10 , tropical 15 , obstetric 15 , pediatric 15 , trauma 59, chest 39 , and general 41 .

The discussion of the study results will be presented according to the same order of the tables as explained in the previous section. Studying the personal characteristics of the study sample results revealed that the highest percent of nurses' age ranged between $<25$ to $<35$ years old. This result agreed with (Kotzer et al., 2006) in their research, who stated that respondents primarily ranged in age from 20 to 35 years, while (Kim et al., 2008), found that most of nurses ages from 35 up to 53 years. All of the studied nurses were females, which indicates that the nursing in ICU still depends on women rather than men because hospitals in Upper Egypt prefer women nurses than men nurses in intensive care units.

This is consistent with (Keshk, Qalawa \& Aly 2012), who had investigated performance obstacles among ICU Nurses in Damanhur Teaching Hospital. They found that female nurses were (98\%).On the contrary Seada \& El Banan (2016), who had investigated performance obstacles in New Kaser El
Ainy found that only about half of nurses been females.

Regarding nurse's qualification and marital status, the current study shows that nearly half of the studied nurses had diploma of secondary nursing school (5 years) and were married. On the contrary Keshk, Qalawa \& Aly (2012), found that more than two thirds of the studied nurses had nursing diploma and $\mathbf{9 8 . 3 \%}$ ) were married. This may be due to the system followed by nursing administration department since 5 years ago in which it has been replacing diploma degree nurses by bachelors' degree and technical health institute nurses, as they were more qualified and knowledgeable. In addition, the result revealed that two third of nurses have experience ranged between $1-<5$ years in their job. This may be caused by the fact that the system of nursing administration office was doing change of $15 \%$ from the nurses in intensive care annually according to seniority

This is inconsistent with Keshk, Qalawa \& Aly (2012), who stated that the experience of one third of the study nurses worked in ICU was ranged between (4-6) years. At the same time it is in agreement with the study conducted by Kotzer et al., (2006), who stated that the experience of nurses worked in ICU had less than 6 years experience.

The findings of the present study revealed also that more than one third were working in the morning shift, more than half of them had no assistant nurses in units, more than two thirds of them reported that two patients were assigned to one nurse over the night shift (Figure, 1, 2, and 3).

In the same line, (seada \& El Banan 2016) who had investigated performance obstacles in New Kaser El Ainy stated that nearly two thirds of the studied nurses reported that there was one assistant nurse was available over the shift, and show that half of them were responsible for two patients.

Regarding performance obstacles related to physical work environment: the findings of the present study revealed that more than half of the studied nurses do not find a place to sit down to do paperwork in the unit, These findings are similar to that of Carayon \& Gürses (2007), in their study of ICU's nursing workload who found that the difficulty in finding a place to sit down and do the paperwork was one of the common performance obstacles.

Moreover, there was enough space between beds, and nearly half of nurses had no a hand washing basins in nursing station. More than one third of them said that work place was crowded, storage place was far from the unit, and the space area was not commensurate with the patient researcher's point of view, some of ICU was not designed from the beginning for this purpose. 
Moreover, according to the results of the present study the majority of study nurses reported that they had no enough staff to handle the number of patients. From The researcher's point of view the reason was due to lack of cooperation from Ministry of Health to appoint new nurses. Another cause may be increased child-care leave to escape from the pressure of work.

These findings are in the same line with that of (Ibrahim et al., 2015) who found that among ICU performance obstacles were work organization, staff shortage and nursing tasks, (Gurses \&Carayon, 2007) \& (Beckstrand, \& Kirchhoff, 2005) who reported that most frequent obstacles to performance in ICU were staff shortage and high workload.

In addition, more than half of the studied nurses stated that there were no isolation rooms for patients who need isolation. From the researcher's point of view, there was poor ICU engineering design and the space of ICU was small.

Regarding performance obstacles related to family relations: two thirds of the studied nurses were suffering from distraction from patients' family members due to receiving many phone calls or messages from them, (Table, 3 ).

From the researcher's point of view, the nurses have no patient family relationships, may be due to "inadequate time for nurses to deal with patient families needs, nurses' high stress levels and high workload due to the characteristics of their job, lack of training and knowledge of nurses to meet the families' psychosocial needs and the inadequate selfconfidence of the nurse regarding his or her abilities and competence in the job. The characteristics of their job, lack of training and knowledge of nurses to meet the families' psychosocial needs and the inadequate self-confidence of the nurse regarding his or her abilities and competence in the job. This result was inconsistent with (Sangala et al., 2015) they found that the predominant needs of the families were met through telephone conversations with ICU nurses to take information about their patient's conditions and were readily accessible at all times of the day, and that the nurses provided a valuable source of information and support for family members over the telephone.

Obstacles related to supplies and equipment revealed that more than half of the studied nurses were suffering from delay in getting medications from pharmacy (Table, 4). There was a shortage in pharmacists. Therefore, each one of this pharmacist was responsible for many departments. This led to presence of many nurses needs to receive medication at the same time, which led to delay in getting medications.

This result is congruent with the study of (Mohammadi et al., 2016) which was conducted at
ICU and NICUs as a comparative study between Jazan General Hospital, KSA Sabia General Hospital, Abu Arish General Hospital in Egypt. He found that one of the most critical performance obstacles was the delay in getting medications.

Shortage of supplies is another factor hindering performance, while two-thirds of them had to wait to use a piece of equipment because someone else was using it. More than half of the studied nurses were using equipment, which were in poor condition and half of them were spending much time searching for equipment and supplies in their units. From the researcher's point of view, the intensive care units were not suitably equipped because the quantity of supplies was not enough relative to the increased the number of patients (Table, 5).

This result is congruent with that of (Seada, \& El Banan, 2016) who found that the most critical performance obstacles included were the equipment which were in poor condition, waiting for using a piece of equipment and spending much time seeking supplies from the central stock.

Regarding performance obstacles of information transfer \& Communication elements: three different issues related to nurse-physician communication were identified as performance obstacles by critical care nurses (inadequate information from physicians, delay in seeing new medical orders for patient(s), and spending much time figuring out which physician to contact about one of their patients) (Table, 5). From the researcher's point of view, which the physicians responsible for many duties may cause at the same time.

Tammelleo (2001) stated that nurses might not get the information they need from physicians during both day and night shifts. During the day shift, physicians may not be available immediately to respond to nurses' questions because they face other demands such as being in surgery or attending meetings. Ineffective communication between nurses and physicians has been linked to medication errors, patients' injuries, and patients' death.

Narasimhan et al., (2006), Gurses \& Xiao (2006), suggested that methods should be adopted for improving nurse-physician communication such as developing and using new information tools for multidisciplinary rounds e.g. a daily goals worksheet to ensure the clarity of what is discussed and prevent physicians from forgetting to discuss issues regarding the important for patient care. The researcher's point of view, that the university hospitals are teaching hospitals so that the role of the physician is not only about the treatment of patients but teaching new physicians and other duties out of ICU (eg. surgical operation or trauma unit). 
Regarding performance obstacles for (cooperation) among nursing team, shows that two thirds of nurses had adequate chance to help other nurses with their patients' needs, more than three quarters had help from other nurses and unit clerks, and about three quarters had help from assistants (Table, 6). From the researcher's point of view because of staff shortage in some intensive care units, nurses were forced to cooperate with each other to do their work; this created a spirit of cooperation among them.

This is consistent with Keshk, Qalawa \& Aly, (2012), who found that more than half of nurses were able to help other nurses, more than three quarters had help from others, more than half had help from assistants and more than one quarter had help from unit clerks.

Wolfe, (2012) mentioned that a good ward clerk should be able to work efficiently amidst a very fastpaced working environment. They should be able to effectively follow the hospital's record-keeping systems and procedures. They should also have the presence of mind to give assistance when necessary.

Regarding the elements of records and reports: Two-thirds of the studied nurses reported that when serious mistakes occurred, this was recorded, nearly two-thirds of them were recording any problem that occurred for patients (Table, 7). From the researcher's point of view, this was because of the continuous follow-up from hospitals administration and the head of the departments and nursing supervisors, and some of ICUs used hospital information system.

Regarding other performance obstacles that occurred during the shift, which causes high workload as suggested by the studied nurses included ineffective interpersonal relationship, shortage in staff, and suffering from sudden absence of nurses (Table, 8). From the researcher's point of view, the ineffective interpersonal relationship was due to work stress resulting from shortage in staff. The sudden absence of nurses resulted from them living in a distant places and sometimes transportation were not available.

In addition, as presented in table (8) there was a clear difference between the mean of subitems of performance obstacle in ICUs specialty There was statistically highly significant difference between performance obstacles related to; physical work environment, family relations, supplies \& equipment, Information transfer \& communication, records and reports and total performance obstacles with ICUs specialty $(* * * p<0.000)$. From the researcher's point of view, difference patient, length, may cause this of stay, different design systems of the units and number of bed.
Assessment of performance obstacles is essential in ICUs to ensure the quality of care, increase patient safety and reduce the risk of adverse events that may occur by performance obstacles.

\section{Conclusions}

The most influential items of performance obstacles were nursing staff was not enough to handle the number of patient, had difficulty finding a space to sit down and do any paperwork in his unit, nurses suffering from distraction from the patients' family, nurses had no equipment because someone else was using it. More than half of them reported a delaying in getting medications from pharmacy.

\section{Recommendations}

- When planning for a new or renovated critical care units, the health care facility should consults an expert in the field of hospital design as well as taking consideration about nurses and patients needs related to infrastructure of the unit.

- Providing suitable and enough supplies in the intensive care units and taking care for continued maintenance of equipment for patient safety.

- Adequate spacing must be present for equipment, performing procedures at the bedside and for nurses sitting to do prepare paper work.

- Communicate effectively with the Ministry of Health asking for commissioned a number of nurses and pharmacist commensurate with the volume of work done so redistribution of nurses all over the country must be done.

\section{References}

1. Beckstrand R., \& Kirchhoff T., (2005): Providing End Of Life Care To Patients: Critical Care Nurses Perceived Obstacles and supportiveBehaviors Am J Crit Care 14 (5): 395- 403.

2. Carayon, P., BT Karsh A., Gurses, C., Alvarado, M., Smith, P., Flatley Brennan (2006): "Work system design for patient safety: the SEIPS model." Quality and Safety in Health Care 15.suppl 1 i50-i58.Management 34(10), 50-53.

3. Grensing, P., (2001): High-maintenance employees. HR Magazine, 46, 86-91.

4. Gurses A., \& Carayon, B., (2007): Pronovost, Wu, \& Sexton, 2004; Sexton, Thomas, \& Helmreich, (2000): Performance obstacles of intensive care nurses. Nursing Research, 56(3), 185-94

5. Gurses A., Carayon $P$ \& Wall $M$ (2009): Impact of performance obstacles on intensive care nurses' workload, perceived quality and 
safety of care, and quality of working life. Health Serv Res 44, 422-443.

6. Gurses, A., (2005): "Performance Obstacles and Facilitators, Workload, Quality of Working Life and Quality and Safety of Care among Intensive Care Nurses.' Doctoral dissertation. University of Wisconsin-Madison.

7. Gurses, A., \& Xiao, Y., (2006): A systematic review of the Literature on multidisciplinary rounds to design information technology. Journal of the American Medical Informatics Association, 13: 267-276.

8. Ibrahim, sleem W., Hamdy F., Khafagy M., (2015): Association between performance obstacles and quality of work life among intensive care nurses. Mansoura Nursing Journal (MNJ) 147 Vol.2 No.1 ISSN: $18235-$ 2015.

9. Institute of Medicine. (2004): Keeping Patients Safe: Transforming the Work Environment of Nurses.

10. Keshk L., Qalawa S., \& Aly A., (2102): Performance Obstacles Experience Among Critical Care Nurses In Damanhur Teaching Hospital. Life Science Journal9 (2).

11. Kim Y., Heerey M., \& Kols A., (2008): Factors that enable nurse-patient communication in a family planning context: A positive deviance study, International Journal of Nursing Studies, 45: 1411- 1421.

12. Kotzer M., Koepping D., LeDuc K., (2006): Perceived Nursing Work Environment of Acute Care Pediatric Nurses .PEDIATRIC NURSING/ 32(4):327-33

13. Mohammadi M., Mazloumi A., Kazemi Z., Zeraati H., (2016): Evaluation of Mental Workload among ICU Ward's Nurses. Health Promot Perspect. 2016 Jan 30; 5(4):280-7. \{33\}.

14. Narasimhan, M., Eisen, L., Mahoney, C., Acerra, F., \& Rosen, M., (2006): Improving nurse-physician communication and satisfaction in the intensive care unit with a daily goals worksheet. American Journal of Care, 15: 217222

15. Sangala N., Horscraft S., McGowan A., \& Baldwin F., (2015): Telephone communication on the ICU: What nurses say to families? Intensive Care Med Exp. 2015 Dec; 3 (Suppl 1): A713.

16. Schmalenberg, C., \& Marlene K., (2007): "Types of intensive care units with the healthiest, most productive work environments." American Journal of Critical Care 16.5 458-468.

17. Seada, A., \& El Banan, S., (2016): Performance obstacles and its relation to the
Perceived Quality of patient care and quality of working life among ICU nurses IOSR Journal of nursing and health Science (IOSR- JNHS) eISSN:2320-n1959.p-ISSN:2320-1940 volume 5,ver.II (sep- oct.2016)pp 53-67.

18. Tammelleo, A., (2001): Failure to keep physicians informed Death results. Nursing Law's Regan Report, 41: 2.

19. Tucker, A., \& Edmondson, A., (2003): "Why hospitals do not learn from failures: Organizational and psychological dynamics that inhibit system change. California Management Review, Vol 45, 2: P.p .1-18.

20. Ulrich, R., Zimring, C., Zhu, X., DuBose, J., Seo, H., Choi, Y., Joseph, A., (2008): A Review of the Research Literature on EvidenceBased Healthcare Design. Health Environments Research \& Design Journal, 1(3), 61-125.

21. 21- Wolfe M., (2012): What Causes Poor Customer Service in Hospitals? http://www.ehow.com/list_7363692_causespoorcustomer-service-hospitals_.htmlDemand Media, Inc. 